\title{
The results of air treatment process modeling at the location of the air curtain in the air suppliers and ventilation shafts
}

\author{
Aleksandr Nikolaev ${ }^{1 *}$, Nikolaj Alymenko ${ }^{1}$, Anton Kamenskih ${ }^{2}$, and Viktor Nikolaev ${ }^{1}$ \\ ${ }^{1}$ Perm National Research Polytechnic University, 29 Komsomolsky av., Perm, 614990, Russia \\ ${ }^{2}$ Mining Institute of the Ural Branch of the Russian Academy of Sciences (78a Sibirskaia st., Perm, \\ 614007, Russia
}

\begin{abstract}
In the existing shaft air heater installations (AHI), that heat the air for air suppliers in cold seasons, a heater channel is used. Some parts of the air from the heater go to the channel, other parts are sucked through a pithead by the general shaft pressure drawdown formed by the main ventilation installation (MVI). When this happens, a mix of two air flows leads to a shaft heat regime violation that can break pressurization of intertubular sealers. The problem of energy saving while airing underground mining enterprises is also very important. The proposed solution of both tasks due to the application of an air curtain is described in the article. In cold seasons the air treatment process should be used and it is offered to place an air curtain in the air suppliers shaft above the place of interface of the calorifer channel to a trunk in order to avoid an infiltration (suction) of air through the pithead. It's recommended to use an air curtain in a ventilation shaft because it reduces external air leaks thereby improving energy efficiency of the MVI work. During the mathematical modeling of ventilation and air preparation process (in SolidWorks Flowsimulation software package) it was found out that the use of the air curtain in the air supply shaft can increase the efficiency of the AHI, and reduce the electricity consumption for ventilation in the ventilation shaft.
\end{abstract}

\section{Introduction}

In cold weather, the air supplied to the mine shafts must be heated to a temperature of not less than $+2{ }^{\circ} \mathrm{C}$, the temperature of this value should correspond to the entire volume of air entering the barrel throughout its cross section. However, conducted in [1-3] studies have shown that these rules are not respected in practice. This is due to the fact that the air supply divide in the two airflow supplied: hot air heater installation in the shaft (AHI) supplied by air heater channel and sucked through the pithead by mine depression. Consequently, in practice, the air supplied from the AHI is heated to temperatures much higher than required, resulting in the barrel is often observed a significant «overheating» air. In the air supply shaft portions are present, the temperature which is slightly above

* Corresponding author: nikolaev0811@,mail.ru 
value of $+2{ }^{\circ} \mathrm{C}$, which indicates the low efficiency of the existing process control method of air handling and proximity to the temperature disturbance in the shaft.

This situation leads to disruption of the pressurization of intertubular sealers, resulting in there is a threat to the integrity of the trunk lining. The presence in the air supply shaft with different temperatures flows becomes the cause of them so-called «airlock» that prevent air entering on them and cause a malfunction of ventilation modes [1].

Thus, temperature rise air in the feed mine to excess results in increased energy costs, work spent on the AHI, i.e. to a waste of energy.

Due to the fact that, according to [4-6] from 30 to $50 \%$ of the total spent on underground mining enterprise power are consumed for ventilation, another important challenge for the production is the need to improve energy efficiency work main ventilation installation (MVI).

The situation described above, in addition increase to energy cost overruns at the MVI and the deterioration of production safety conditions, causing an associated problem - the emergence of between mine shafts negative general natural draft [7-12], ie when injected into the warm air of air supply shaft tends to rise upwards, and cooled in the mine (mine) goes down. This problem is particularly acute for the shallow (up to $500 \mathrm{~m}$ or less) underground mining.

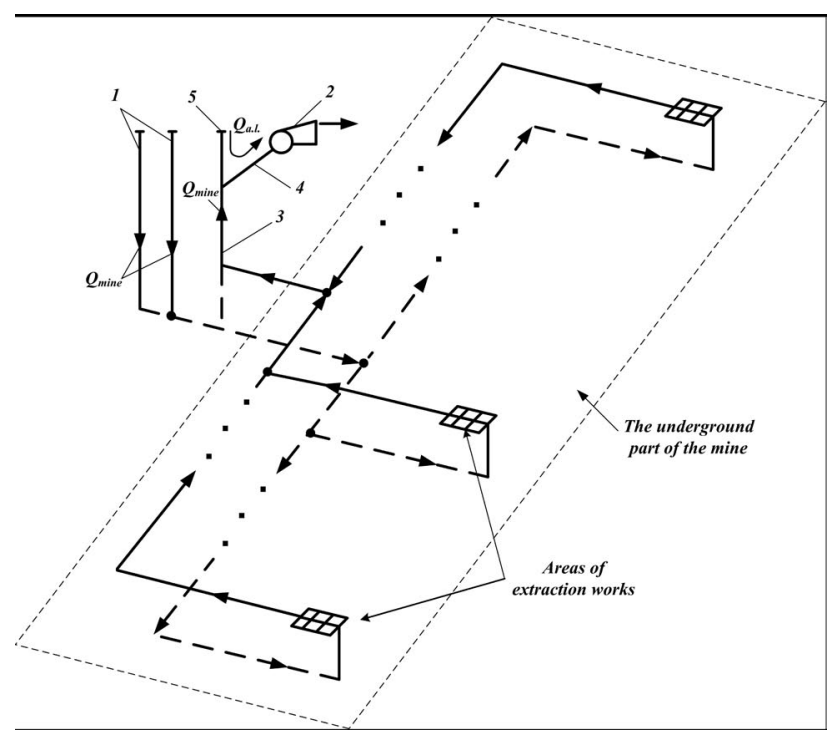

Fig.1. A simplified diagram of the mine operating on the suction method of ventilation

Additionally, inherent to the suction method of ventilation problem - the emergence of outside air leaks [13], for the following reasons. The air in the mine $\left(Q_{\text {mine }}\right)$ is supplied through air suppliers shafts 1 by the underpressure created by the MVI 2, located on the ventilation shaft 3 (Fig. 1). In addition to the air sucked into the mine, with a similar pattern of ventilation in the channel of MVI 4 is also sucked into the outside air through the mouth of the ventilation shaft 5 , which is mixed with the general stream will again be released into the atmosphere. Therefore, in addition to useful work (fresh air injection), the MVI will make useless work due to external air suction (external leakage) $Q_{a . l}$. The quantity of leakage (for example potash mines) according to $[13,14]$ ranges from 9 to $51 \%$, ie there are mines, where the efficiency of the MVI work is only $49 \%$. In this regard, reduction of external (surface) leakage is one of the main directions in the complex of measures to reduce costs in the mining ventilation underground mining enterprise. 


\section{Results}

In order to improve air handling efficiency and reduce electricity costs spent on the work of the MVI, the present study the authors proposed in the air suppliers and ventilation shafts to establish an air curtain (Fig. 2). The air supplier shaft air curtain should ensure infiltration reduction (choke) of the outer cold air through the pithead. In this case, the AHI work will require less energy costs, as well as the normal air mixing process in the shaft. The air curtain in the ventilation shaft is needed to reduce external air leaks $[13,14]$.
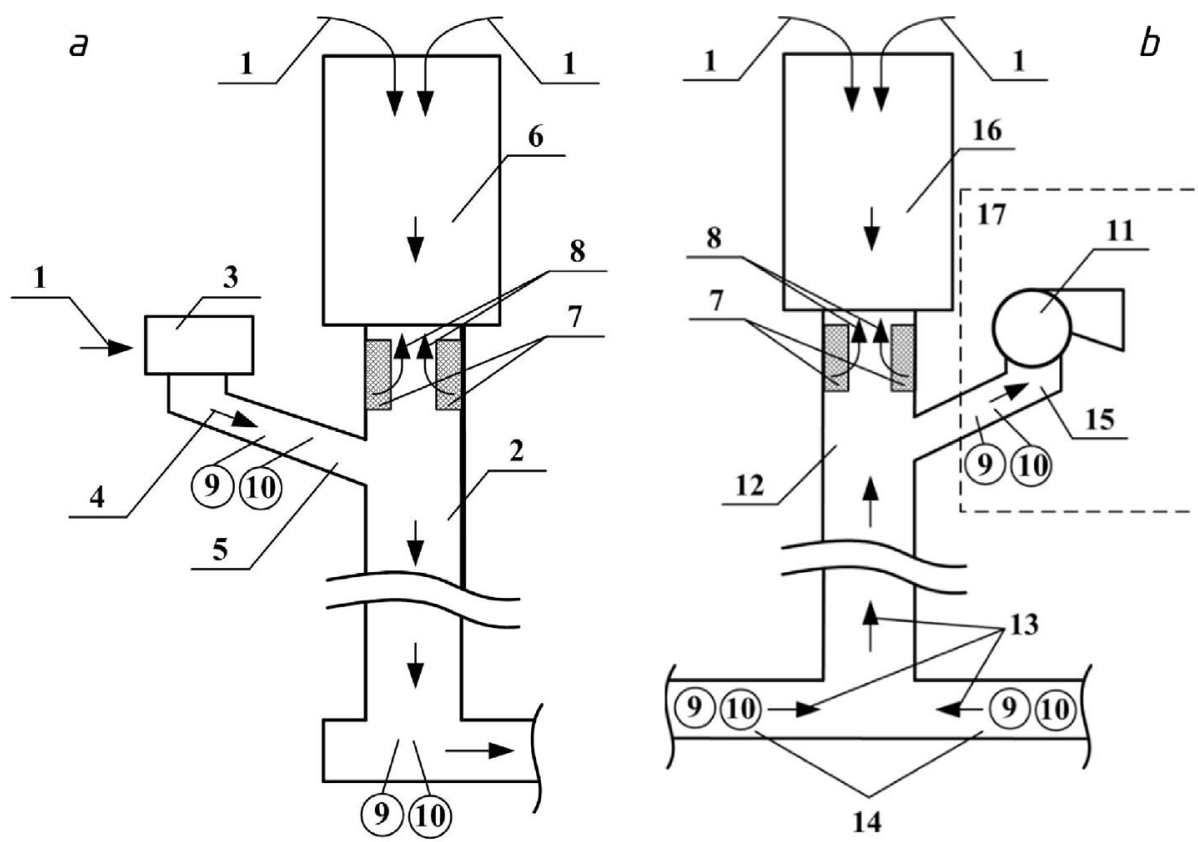

Fig. 2. Implementation of ventilation and air handling proposed method: $a$ - air curtain in the air supplier shaft; $b$ - air curtain in ventilation shaft. 1 - outside air (cold); 2 - air supplier shaft; 3 - AHI; 4 - the heated air; 5 - air heater hot-air channel; 6 - pithead on the air supplier shaft; 7 - air curtain; 8 - the air output from the air curtain; 9 - air flow sensor; 10 - a temperature sensor, a pressure (or density meter); 11 - MVI; 12 - ventilation shaft; 13 - outgoing air for ventilation shaft; 14 - the main ventilation shaft production; 15 - channel of MVI; 16 - pithead on the ventilation shaft; 17 superficial complex MVI

In Fig. 3 shows the layout and operation of the air curtain at the mouth of the shaft. With fans 1 of the air curtain, installed on shelves on one of tiers reinforcement stem 7 shall intake air through the ducts 3 in the place indicated by 4 . The jets of the air curtain is ejected at a speed $V_{r}$ from the dispenser 2, at an acute angle $\alpha$ meet the air flow external air leakage. After bending, jet air curtain cover the cross section of the shaft, thereby increasing the aerodynamic resistance of the shaft section from zero mark to interface with the channel. Dispensers air devices are installed on the shelves of one of the reinforcement of the barrel 7 tiers with fans 1 . The place of installation of the air curtain overlaps part of the shaft section of a hollow flooring. The central execution is set 5 longitudinal bulkhead limiting the impact of the jets of the veil at each other. To improve the effectiveness of the air curtain, and set the partition 6 on the perimeter of the flow cross section of the shaft. 


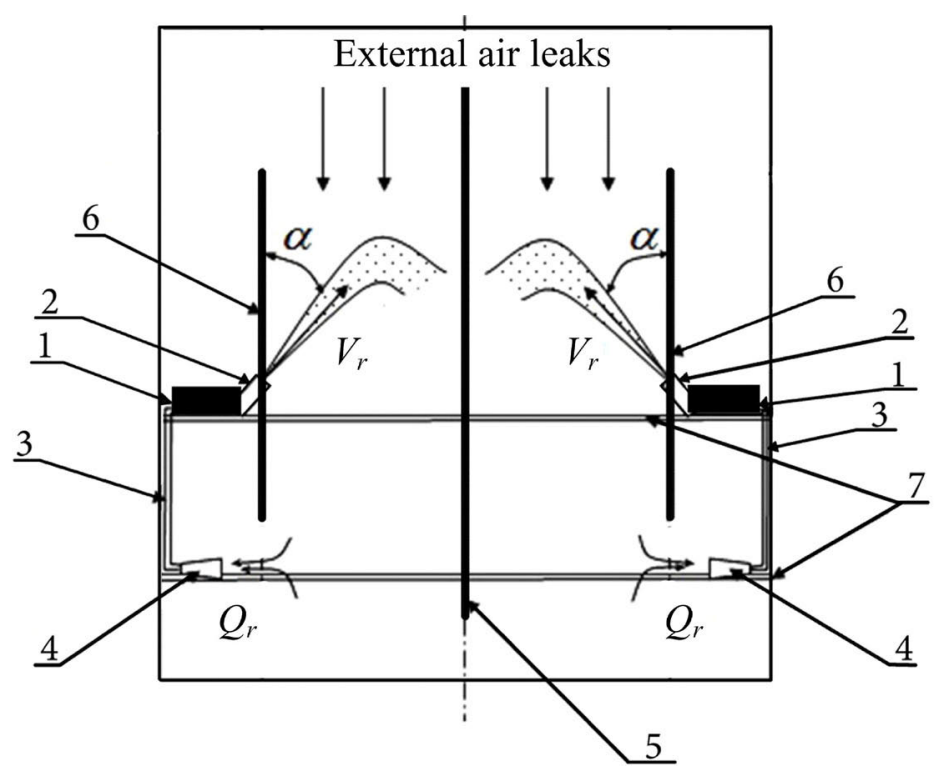

Fig. 3. The layout and operation of the air curtain in the mouth of the shaft: 1 - fan air curtain; 2 - a box for the issuance of air; 3 - pipes (ducts); 4 - the air intake; 5 - longitudinal bulkhead; 6 longitudinal walls (on the perimeter of the section to light); 7 - tier shaft reinforcement

Engineering practice is based on experimental studies that when proper planning usually provides high reliability of experimental studies. A significant drawback in the present conditions of these studies - the high cost and time required for preparation and conduct of such studies. Therefore, an effective measure is the use of parametric calculations (computational studies or numerical simulations). They are accurately simulate physical phenomena that determine the characteristics of the system, with experimental studies needed to test this accuracy. Calculations should be performed using the software, ensure the implementation of the entire set of necessary calculations in a reasonable amount of time with sufficient accuracy.

For a detailed analysis taking into account all the geometric features of the shaft and the proposed construction of the air curtain in the present study carried out a three-dimensional modeling and numerical simulation using computational fluid dynamics methods. Mathematical modeling conducted in the software package SolidWorks Flowsimulation in the supercomputer (system «PGU-Tesla») [15].

The test model is considered a variant design and placement of the air curtain in the mouth of the ventilation shaft. Fig. 4 shows a model of the placement of the air curtain in the mouth of the ventilation shaft, which is constructed according to the geometrical dimensions of the barrel, and a scheme for allocating the air curtain in his mouth (Fig. 3).

\section{Discussion}

Research carried out on the three-dimensional mathematical model with different numbers of cells (the number of computational cells was brought to 3 million, thanks to highperformance computing system «PGU-Tesla»), which made it possible to obtain reliable results. Based on the results of the study, the calculations must also be carried out on a computational grid with the number of cells at least 3 million, as in this case the results obtained with the smallest deviation from the mean. 
In Fig. 5 shows the results of modeling air handling method of the currently accepted (Fig. 5, a) and by using an air curtain (Fig. 5, b).

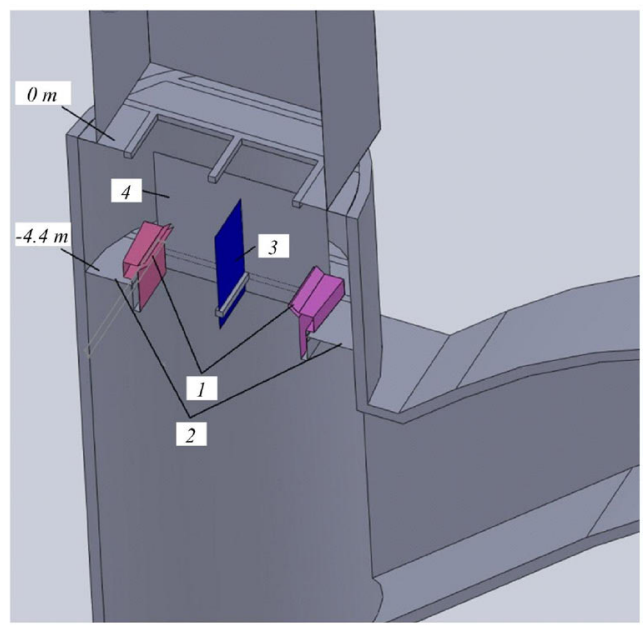

Fig. 4. The air curtain in the mouth of the shaft: 1 - a box for the issuance of air (fans air curtain); 2 shelves; 3 - longitudinal bulkhead; 4 - transverse partition
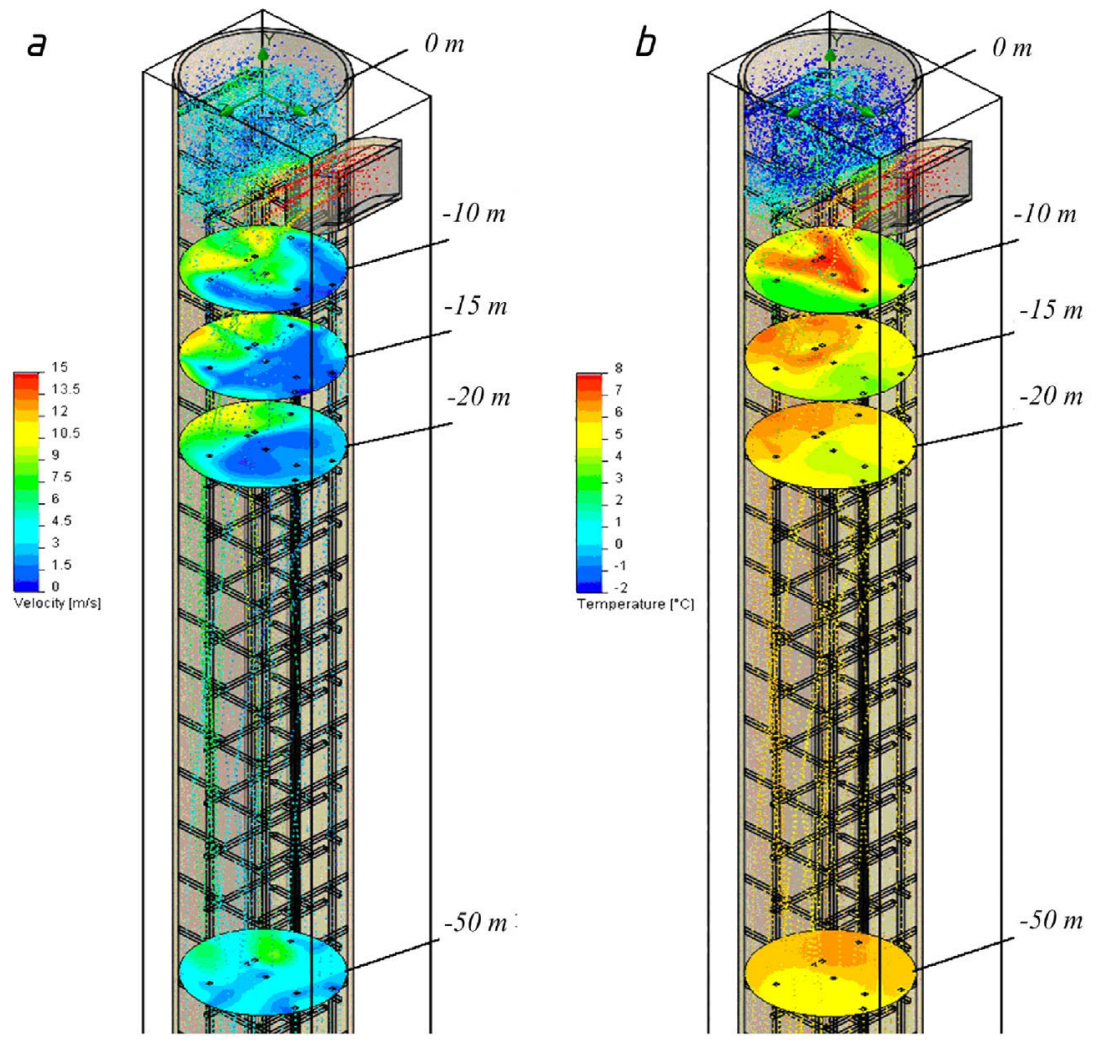

Fig. 5. Air temperature distribution over the cross section of air supplier shaft at different depths by mixing cold and hot air using an air curtain installed in the mouth of the barrel: $20{ }^{\circ} \mathrm{C}$ cold air $(20$ $\left.\mathrm{m}^{3} / \mathrm{s}\right)$, a warm air $+8{ }^{\circ} \mathrm{C}\left(147 \mathrm{~m}^{3} / \mathrm{s}\right): a$ - without air curtain in the air supplier shaft; $b$ - using an air curtain in the air supplier shaft 
As seen from the figure, as compared with the inventive method has used a number of advantages:

Firstly, in the air supplier shaft are no zones with temperature close to (or even more below) $+2{ }^{\circ} \mathrm{C}$, e.g. obsolescence threat violation the pressurization of intertubular sealers. At the same time work on the AHI will need a smaller amount of energy, ie, reduce the cost of air handling. Compared with the amount of energy spent on the work of the AHI, the electricity costs spent on the work of the air curtain disproportionately small. Moreover, due to the fact in the shaft will not be necessary to heat the air to a higher temperature, between the trunks decrease negative (or increase positive) mine natural draft, resulting in the MVI will decrease energy consumption at times more than what is required in the operation of the air curtain.

Secondly, already at around $-20 \mathrm{~m}$ thermal distribution on the cross section substantially uniform air supplier shaft, i.e. the likelihood of «airlock» it is virtually absent.

During the process of mathematical modeling of the air curtain in the ventilation shaft (Fig. 6), it was found that when the external air leaks accepted conditions will decrease from $60.43 \mathrm{~m}^{3} / \mathrm{s}$ to $26.27 \mathrm{~m}^{3} / \mathrm{s}$, ie, approximately $43.5 \%$, and the work of the MVI instead $443.80 \mathrm{~m}^{3} / \mathrm{s}$ need to $409.64 \mathrm{~m}^{3} / \mathrm{s}$.
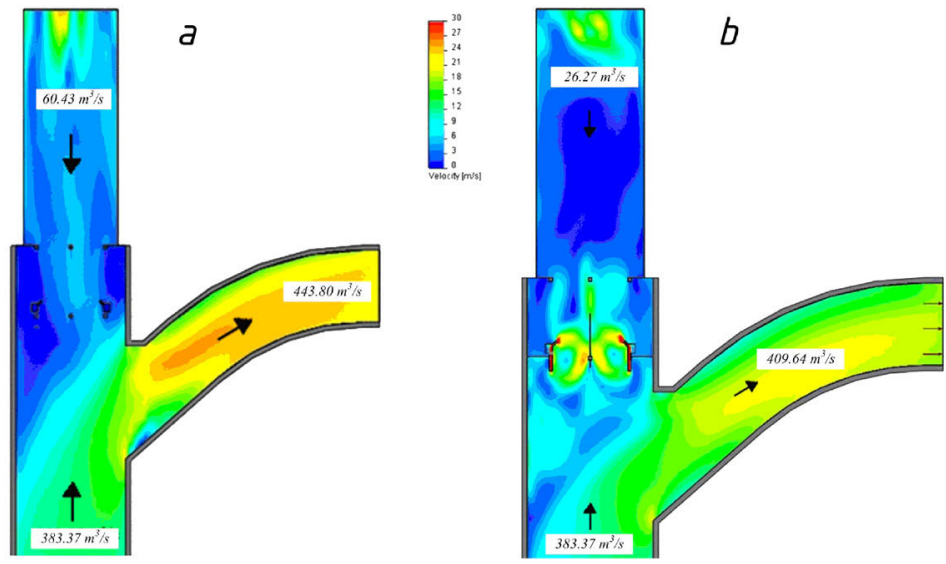

Fig. 6. The result of mathematical modeling of air distribution of air flow in ventilation shaft: $a-$ without air curtain in ventilation shaft; $b$ - using an air curtain in the ventilation shaft

In the action of the air curtain aerodynamic resistance of the shaft portion of the zero mark to interface with ventilation shaft increases, ie, increases aerodynamic drag of external air leaks. At the same time the aerodynamic resistance of the mine remains unchanged, and the aerodynamic resistance of the ventilation network, which operates the fan increases. Operating point MVI moves the aerodynamic characteristics of the fan in the region of lower pressure, causing by changing the installation angle of the blades of the axial guide vane changes the work of the MVI on a more economical mode. At the same amount of fresh air entering the underground mining company remains unchanged, and the consumption of electricity is reduced MVI.

\section{Conclusion}

Thus, in the course of mathematical modeling established that the proposed method of using an air curtain in the air supplier and ventilation shafts will prevent the negative and harmful processes associated with the uneven distribution of temperature field on the shaft cross section, overruns of energy to work AHI, and will save electricity, spent on the work of the MVI. 


\section{References}

1. N.I. Alymenko, A.A. Kamenskikh, A.V. Nikolaev, A.I. Petrov, Eur. Min. 26, 45 (2016).

2. K. Hanjalic, B.E. Launder, J. Fluid Mech., 52, 609, 1972.

3. M.J. McPherson, G. Robinson, Mine vent. South Africa, 33, 145, 1980.

4. B.K. Belle, North American Mine vent. Symp., 427, 2008.

5. J.J.L. Du Plessis, W.M. Marx, and C. Nell, The Journal of The Southern African Instit. of Min. and Metall., 114, 1033, 2014.

6. G. Cheng, M. Qi, J. Zhang, W. Wang, and Y. Cheng, Procedia Eng., 45, 311, 2012.

7. W.E. Bruce, Natural draft: its measurement and modeling in underground mine ventilation systems (US: Dept. of Labor, Mine Safety and Health Administr., 1986).

8. P.F. Linden, Annual Review of Fluid Mechanics, 31, 201, 1999.

9. Jianwei Cheng, Yan Wu, Haiming Xu, Jin Liu, Yekang Yang, Huangjun Deng, Yi Wang, Tunneling and Underground Space Technology, 45, 166, 2015.

10. Van Ulden, A. Holtslag, J. Clim. Appl. Meteorol., 24, 1196, 1985.

11. N.I. Alymenko, A.V. Nikolaev, Journal of Mining Science, 47, 636 (2011).

12. G. B. Lyal'kina, A.V. Nikolaev, Journal of Mining Science, 51, 342 (2015).

13. Y. Verma, Mining Engineering (Gr. Brit.), 140, 47, 1980.

14. P. Berry, in World Mining Congress, New Delhi, 3, 1, 1984.

15. R. E. Barr, D. Juricic, T. J. Krueger, Engineering and Computer Graphics Workbook Using Solidworks 2015 (SDC Publications, 2015). 